\title{
Informação arquivada: acesso e memória
}

\author{
Archived Information: access and memory
}

\author{
Maria Leandra BIZELLo (1) \\ Universidade Estadual Paulista Júlio de Mesquita Filho - UNESP, Departamento de Ciência de Informaç- \\ ão, Av. Hygino Muzzi Filho, 737, Campus Universitário, CEP. 17525900 - Marília, SP, Brasil, Caixa- \\ Postal: 181, mleandra23@gmail.com
}

\begin{abstract}
Resumen
Se reflexiona sobre dos aspectos centrales de la ciencia de la información y, más específicamente, de la archivología: el acceso a la información científica y la memoria. Se focaliza la reflexión en la información científica, o sea, aquella producida y guardada en instituciones científicas y para la ciencia, en dos instituciones concretas: la Universidad Estatal de Campinas (UNICAMP) y la Universidad Estatal Paulista "Júlio de Mesquita Filho" (UNESP). El estudio de acceso a la información y de la memoria científica está en lo que podemos denominar la frontera entre los estudios del archivo y de la sociedad. La reflexión también es de frontera, en la medida en que establece relaciones conceptuales con otras áreas de las ciencias humanas como la historia, la sociología y la política.
\end{abstract}

Palabras clave: Información. Memoria. Acceso. Archivo. Ciencia de la Información. Archivología.

\section{Introdução}

O estudo apresentado faz parte das diversas preocupações da linha de pesquisa Informação e Sociedade, do Departamento de Ciência da Informação da Unesp - Marília, e do Grupo de Estudos Memória. As discussões que levantamos fazem parte das reuniões e de algumas pesquisas desenvolvidas por seus participantes voltadas para o estudo do acesso à informação nos arquivos históricos e o trabalho que desenvolvem com a memória.

A memória sempre foi um atributo do arquivo como instituição. O papel social do arquivo está tradicionalmente ligado à guarda da documentação histórica de uma dada sociedade e, portanto, falar de arquivo é se referir ao resgate da memória. No entanto, essa relação que tende a ser natural passa por uma revisão e o que contribui para ela são dois pontos: a gestão documental e a compreensão do arquivo como um lugar de memória.

Na gestão documental, a compreensão do perfil do arquivista e o tratamento documental mudaram: o profissional não se dedica tão somente ao trabalho no arquivo permanente tratando os

\begin{abstract}
This article reflects about two aspects of information science and, more specifically, of archival science: the access to information and memory. Both aspects are referred to scientific information, that is, that information produced and kept in scientific institutions to support science; and to two specific institutions: the State University of Campinas (UNICAMP) and the São Paulo State University "Júlio de Mesquita Filho" (UNESP). The study of access to scientific information and memory is in the frontier between social and archival studies. The reflection is also one in the frontier, as pretends to establish conceptual relations with other areas of the human sciences as history, sociology and politics.
\end{abstract}

Keywords: Information. Memory. Access. Archive. Information Science. Archival Science.

papéis de valor histórico, ele atua ativamente na administração de papéis em uso constante, isto é, o arquivista pensa no todo do documento, no seu ciclo de vida, da gênese à destinação final do documento, na eliminação ou na sua guarda permanente. Ele influencia as decisões tomadas pelos administradores, sendo responsável pela racionalização e otimização do trabalho burocrático. A avaliação documental nos arquivos correntes pode ser considerada um momento essencial de atuação do arquivista como líder de equipe, pois para que a avaliação aconteça, ele deve consultar profissionais de outras áreas fundamentais para o entendimento da ação do documento, qual sua significação jurídica e seu trâmite.

Se o arquivista é atuante nessa fase em que o documento tem seu valor primário, ele tem todas as condições de pensar o documento quando da guarda permanente ao estabelecer o ciclo de vida documental, sendo estes os fundamentos do arquivo permanente e da memória.

O espaço do arquivo implica muito mais que estantes onde os documentos são acondicionados, laboratórios de restauração, salas de tratamento técnico, ele comporta espaço para 
pesquisadores e cidadãos à procura de informações.

Assim o arquivista é um influente profissional da informação não apenas porque trabalha com ela e a pensa em seu fluxo no arquivo, mas faz um trabalho essencial de mediação entre a informação produzida e guardada e aqueles que necessitam dela em algum momento de suas vidas.

\section{O acesso à informação}

O documento arquivístico é a materialização da informação ainda em um plano abstrato, e ela "representa uma sucessão de atos ou fragmentos que possam ser definidos como fatos." (Lopes, 1996, p. 26).

Há o tratamento arquivístico desse documento com informação registrada que tem o caráter probatório, tanto quando está em atividade administrativa no arquivo corrente, como quando é prova no processo de avaliação e seu destino é a guarda permanente. No arquivo histórico a informação registrada, depois de processada, serve ao usuário que a transformará em conhecimento.

De maneira mais específica as instituições de ensino superior produzem informação registrada que dizem respeito a ela mesma, a sua administração, à produção científica ligada ao ensino, à extensão e à pesquisa.

A informação registrada voltada ao ensino, à pesquisa e à extensão acontece das mais diferentes maneiras. Podemos elencá-las como aquelas que se voltam para a administração das atividades escolares e referentes ao trabalho do professor na sala de aula; outras dizem respeito a esse mesmo professor que, ao desenvolver pesquisa e extensão, também registra essas atividades em projetos financiados por agências responsáveis pelo fomento à pesquisa científica. Os projetos voltados para a comunidade, os de extensão, registram as atividades que os professores desenvolvem na relação que a universidade estabelece com a comunidade na qual está inserida.

Podemos notar que, nas instituições de ensino, a informação registrada é probatória da ação da atividade do professor/pesquisador em diversas dimensões. É, no entanto, na pesquisa que a informação materializada não é produzida apenas na universidade, mas depende de uma série de relações que a instituição estabelece com a sociedade.

Os arquivos históricos e centros de documentação dessas instituições de ensino superior são responsáveis por guardar documentos de interesse à pesquisa desenvolvida pelo corpo de pesquisadores que ali atua e, numa dimensão mais ampla, a todos os cidadãos que de alguma maneira queiram ou necessitem deles.

Há, portanto, usuários mais específicos e outros não tão especializados, mas também desejam debruçar-se sobre a informação registrada e materializada para gerar conhecimento. $\mathrm{O}$ acesso à informação é, pois, um momento em que o arquivista é o mediador da informação organizada e que gerará conhecimento a partir do trabalho do pesquisador.

Os processos de disseminação da informação não se restringem aos instrumentos de pesquisa voltados a sua recuperação como guias, catálogos e índices, hoje outras formas de recuperação da informação são utilizadas com propostas de disseminação da informação que também levam à difusão da instituição e projetos desenvolvidos por pesquisadores internos.

\subsection{Da informação à memória}

A Universidade Estadual Paulista "Júlio de Mesquita Filho" (UNESP) e a Universidade Estadual de Campinas (Unicamp) possuem centros de documentação e arquivos históricos que nos permitem fazer reflexões sobre o fluxo informacional, e mais detidamente para nosso estudo, o acesso à informação.

Vamos deter nossa primeira análise em duas dessas unidades de informação: o Centro de Documentação e Memória da UNESP - CEDEM e o Arquivo Edgard Leuenroth - AEL, na UNICAMP.

O CEDEM - UNESP, em atividade desde 1987, tem "[...] como objetivos a realização de pesquisas, a preservação de documentos e sua difusão." (http://www.cedem.unesp.br/apresent.htm) Esse trecho do texto de apresentação que reproduzimos acima está na página do Centro de Documentação e Memória que por sua vez está no portal da UNESP. Ali o usuário poderá ter o primeiro contato com o CEDEM, explorando as possibilidades dadas pela página virtual.

As informações procuram dar conta do corpo técnico, das publicações, dos eventos realizados no Centro, do acervo e de que maneira o usuário entra em contato com o Cedem para obter informações que não conseguiu na página, podendo preencher um cadastro para estabelecimento de uma relação maior com a instituição.

O Arquivo Edgard Leuenroth possui, desde 1974 quando iniciou suas atividades, uma pro- 
posta que parte de um acervo muito específico a do militante anarquista Edgard Leuenroth e

Inicialmente, propunha-se a preservar e divulgar a memória operária do Brasil Republicano, porém, com o passar dos anos e a crescente doação de fundos e coleções documentais, o AEL ampliou sua temática. (http://www.ifch.unicamp.br/ael/)

Através da página do Arquivo Edgard Leuenroth o pesquisador tem acesso aos acervos que custodia, publicações, aos técnicos que ali trabalham e uma preocupação centrada no usuário oferecendo o cadastro; há também um boletim enviado pela internet no qual o usuário recebe informações sobre cursos voltados para a arquivologia, museologia, restauração, história, sociologia, política, que acontecem no país, além de informações sobre a documentação recebida pelo Arquivo.

Essas duas instituições voltadas para a memória procuram ampliar a disseminação da informação, mas, e principalmente, centram-se na divulgação dos documentos que guardam e produzem.

\section{Memória}

O conceito de memória para Jacques Le Goff está intimamente ligado à ciência e à história como tal. Dessa forma, estudar a memória é também delimitar uma fronteira muito tênue entre as diversas ciências que se ocupam dela e por outro lado, utilizar tais ciências para sua compreensão. Segundo Le Goff (1990), esse conjunto de áreas científicas que se debruçam sobre o mesmo objeto podem entender a memória (Le Goff, 1990, p. 423):

A memória, como propriedade de conservar certas informações, remete-nos em primeiro lugar a um conjunto de funções psíquicas, graças às quais o homem pode atualizar impressões ou informações passadas, ou que ele representa como passadas.

No entanto, para uma compreensão mais ampla da dimensão da memória, Le Goff a estuda historicamente. Baseando-se em LeroiGourhan, aborda essencialmente a memória coletiva das sociedades e as relações que desenvolve com a história; dividindo a história da memória coletiva em cinco períodos (Le Goff, 1990, p. 427):

1) a memória étnica nas sociedades sem escrita, ditas "selvagens"; 2) o desenvolvimento da memória, da oralidade à escrita, da Pré-história à Antigüidade; 3) a memória medieval, em equilíbrio entre o oral e o escrito; 4) os progressos da memória escrita, do século XVI aos nossos dias; 5 ) os desenvolvimentos atuais da memória.
Dessa periodização interessa-nos o quarto e o quinto períodos. Neles a memória se expande em seus suportes. Lentamente, essa expansão acontece com a imprensa, no fim da Idade Média. Até então, a produção e transmissão da memória eram essencialmente atividades orais, mesmo que a escrita tenha aparecido possibilitando outra maneira de guardar e produzir memória.

A memória coletiva das sociedades sem escrita está ligada ao mito e à narração. Nela não há preocupação da reprodução palavra por palavra, mas uma reconstrução generativa (Le Goff, 1990 , p. 430), ou seja, a narração propõe uma dimensão mais criativa cada vez que o homemmemória evoca um acontecimento que the foi transmitido oralmente, ocorrendo nestes casos diversas versões do mito ou do acontecimento.

A escrita transforma profundamente a memória coletiva, pois permite duas formas de memória: a comemoração, cujo suporte é o "monumento comemorativo de um acontecimento memorável" (Le Goff, 1990, p. 431) e o "documento escrito num suporte especialmente destinado à escrita" (Le Goff, 1990, p. 432). O autor destaca, nesse momento, o caráter de monumento do documento. Há, nessa passagem da memória oral para a memória escrita, um acréscimo.

Mas, voltemos aos períodos importantes para nosso estudo.

A invenção da imprensa possibilitou, ao mesmo tempo, a expansão da memória coletiva e uma "[...] longa agonia da arte da memória [...]" (Le Goff, 1990, p. 457) da Antiguidade e da Idade Média, mergulhada na transmissão oral.

Dicionários, enciclopédias, bibliotecas, museus, moedas, medalhas, selos e uma série de souvenirs são, a partir do século XVIII, suportes da memória coletiva alargada; essa memória tornase múltipla, e nessa multiplicidade ela é apresentada ao indivíduo que, no entanto, não consegue fixá-la integralmente, tal é o seu tamanho.

Jacques Le Goff situa no século XIX e início do século $X X$ dois fenômenos significativos para a memória coletiva: "[...]a construção de monumentos aos mortos" [...]" (Le Goff, 1990, p. 465) e a invenção da fotografia. Esse segundo fenômeno revoluciona a memória na medida em que a multiplica e a democratiza.

No século XX, principalmente após 1950, a eletrônica revoluciona a memória. As máquinas de calcular, a fabricação de cérebros artificiais, os computadores, são máquinas que ultrapassam o cérebro humano, mas em relação à memória humana são auxiliares, não a substituem. Auxi- 
liam como banco de dados - inclusive para a história - ou como instrumentos para a biologia, a medicina dentre outras aplicações.

A memória, para Le Goff, individual ou coletiva, é um elemento essencial na busca da identidade de indivíduos ou de sociedades. É também instrumento e objeto de poder, sempre propício à manipulação. Mas o autor entende que "[...] os profissionais científicos da memória, antropólogos, historiadores, jornalistas, sociólogos [...]" (Le Goff, 1990, p. 477) devem lutar pela democratização da memória social, pois (Le Goff, 1990, p. 477):

A memória, onde cresce a história, que por sua vez a alimenta, procura salvar o passado para servir o presente e o futuro. Devemos trabalhar de forma a que a memória coletiva sirva para a libertação e não para a servidão dos homens.

\subsection{Ainda a memória}

A memória individual para Halbwachs (1990) apóia-se na memória coletiva na medida em que as minhas lembranças são estimuladas pelas lembranças dos outros que fazem parte do grupo a que pertenço. O pertencimento a um grupo reforça a noção de identidade fortalecendo a memória coletiva e social.

Para Paul Ricoeur (1998, p. 18) há um dilema ao se tratar os conceitos de memória individual ou privada e de memória coletiva. A memória individual relaciona-se de maneira possessiva com as lembranças: "Minhas lembranças não são as suas lembranças"; há o que ele chama de sentimento de continuidade e as "estreitas ligações privilegiadas com esquecimento". Existe a memória coletiva? Qual o seu objeto? As lembranças referentes a um determinado evento histórico partem de uma coletividade ou de um indivíduo? Podemos estabelecer fronteiras entre essas lembranças?

A solução desse dilema está na proposta que Ricoeur (1998, p. 20) faz: na "hipótese de uma constituição mútua, cruzada, de duas subjetividades, privada e coletiva". É através da linguagem que lembramos, há uma "mediação narrativa da memória a mais privada" (Ricoeur, 1998, p. 20), mas teremos esse movimento também na memória coletiva.

A idéia de memória está, então, desde a expansão daquilo que não damos mais conta, isto é, não conseguimos mais guardar em nossa própria memória tudo aquilo que desejamos e criamos assim expansões: o computador e seus acessórios, nossas agendas em papel ou digitais.
As mediações são sempre necessárias na medida em que ao querermos guardar para sempre corremos o risco de perdermos cada vez mais, mesmo que nossa memória individual se apóie na coletiva ou nela se entrelace a partir de subjetividades.

\section{Considerações finais}

Nesse artigo, que tece as primeiras reflexões sobre as relações entre o acesso à informação e a memória, podemos considerar que as universidades e seus centros de documentação e arquivos, como vimos pelos exemplos, estão preocupados não apenas em guardar a memória individual ou coletiva, mas em proporcionar ao pesquisador e ao cidadão aproximações maiores daquelas que podemos considerar como tradicionais.

A internet tornou-se também um lugar de memória como nos diz Pierre Nora (1993), na medida em que permite o acesso mais amplo de cidadãos às unidades de informação registrada e organizada; preocupa-se em mostrar caminhos através de publicações que divulgam não apenas os acervos que custodiam, mas o conhecimento produzido a partir deles.

\section{Referências}

Arquivo Edgard Leuenroth. http://www.ifch.unicamp.br/ ael/website-ael_institucional/website-el_historico.htm (2009-05-10).

Centro de Documentação e memória da UNESP. http://www.cedem.unesp.br/apresent.htm (2009-05-10).

Halbwachs, Maurice (1990). A memória coletiva. São Paulo: Vértice, Editora Revista dos Tribunais, 1990.

Le Goff, Jacques (1990). História e memória. trad. Bernardo Leitão et al. Campinas - SP: Editora da Unicamp, 1990.

Lopes, Luís Carlos (1996). A informação e os arquivos: teorias e práticas. $1^{\text {a }}$ ed. Niterói; São Carlos: EdUFF; EdUFSCAR, 1996.

Ricoeur, Paul (1998). Histoire et mémoire. // Baecque, Antoine de \& Delage, Christian (eds.). De l'histoire au cinéma. Bruxelles: Éditions Complexe, 1998. 17-28. 